ISSN 2526-7248 artigo n. 3SPPC1010, pp. 106-115, 2018

\title{
Levantamento de manisfestações patológicas em Estação de tratamento de Esgoto: Estudo de caso em reator UASB
}

\author{
Kudlanvec Jr, Vitor Lorival ${ }^{1}$; Canalle, Rafael ${ }^{2}$; Nunes, Tuane K. Laia ${ }^{3}$; Resende, \\ Elaine C.R.C ${ }^{4}$; Silva, Melissa Dione S. Correia ${ }^{5}$ \\ ${ }^{1}$ Mestre, Universidade Federal do Paraná, vlestrutural@gmail.com \\ ${ }^{2}$ Graduando, Faculdade Educacional Araucária, rafa.c.cwb@gmail.com \\ ${ }^{3}$ Graduanda, Faculdade Educacional Araucária, tuane.laia@hotmail.com \\ ${ }^{4}$ Graduanda, Faculdade Educacional Araucária, elaine.crc@hotmail.com \\ ${ }^{5}$ Graduanda, Faculdade Educacional Araucária, melissadione73@gmail.com
}

\begin{abstract}
Resumo: $\mathrm{O}$ concreto quando exposto à ambientes com classe de agressividade elevada torna-se um material vulnerável, a agentes agressores que interferem diretamente na microestrutura da pasta do cimento. A exposição do concreto à ação de esgoto doméstico caracteriza um ambiente de alta agressividade (Classe IV). $O$ presente trabalho teve como objetivo realizar um levantamento de dados sobre os tipos de manifestações patológicas e um estudo de caso em Estação de Tratamento de Esgoto (ETE), no reator anaeróbio de fluxo ascendente e manta de lodo - (UASB) devido ao microclima formado no interior, pela formação de gás sulfídrico $-\mathrm{H}_{2} \mathrm{~S}$ e Anidrido Carbônico $-\mathrm{CO}_{2}$, a partir de bactérias anaeróbias redutoras de sulfato (dessulfatação). $\mathrm{O} \mathrm{H}_{2} \mathrm{~S}$ é o precursor da formação do ácido sulfúrico biogênico - $\mathrm{H}_{2} \mathrm{SO}_{4}$, responsável pela deterioração do concreto da estrutura. Inicialmente realizou-se uma revisão bibliográfica e elaboração do estudo de caso após visita técnica na ETE na região de Santa Quitéria em Curitiba. A identificação dos tipos de manifestações patológicas foi realizada visualmente e por registros fotográficos, onde foi detectada a deterioração da superfície do concreto do tanque do reator e a visível exposição dos agregados decorrentes do ataque químico, por sulfatos. Fica como sugestão a realização de ensaios mais específicos como: 0 de microscopia eletrônica por varredura - MEV, difração de raios X, resistência à compressão e potencial de corrosão para uma análise mais sucinta da magnitude dos mecanismos e confirmação das possíveis causa e consequências das manifestações observadas.
\end{abstract}

Palavras-chave: concreto, corrosão, manifestação patologica, ataque ácido, estudo de caso.

Abstract: Concrete when exposed to environments with high aggressiveness class becomes a vulnerable material, with aggressive agents interfering directly in its microstructure. The exposure of concrete to the domestic sewage characterizes an environment of high aggressiveness (Class IV). The present work has as objective performing a collection on the types of pathological manifestations and a case study in Sewage Treatment Station (STS), in the Anaerobic UpflowSludgeBlanket (UASB) due to the microclimate in its interior, by the formation of hydrogen sulfide gas $-\mathrm{H}_{2} \mathrm{~S}$ and $\mathrm{CO}_{2}$ anhydride, from anaerobic sulfate reducing bacteria (desulfatation). $\mathrm{H}_{2} \mathrm{~S}$ is the precursor of the formation of the biogenic sulfuric acid $-\mathrm{H}_{2} \mathrm{SO}_{4}$, responsible for the deterioration of the concrete of the structure. Initially a bibliographic review and elaboration of the case study was carried out after a technical visit in the STS in the Santa Quitéria region of Curitiba. The identification of the types of pathological manifestations was performed visually and by photographic records, where the deterioration of the concrete surface of the reactor tank and the visible exposure of the aggregates due to the chemical attack by sulfates were detected. More specific tests such as the scanning electron microscopy (SEM), X-ray diffraction, compression resistance and corrosion potential for a more succinct analysis of the mechanisms and confirmation of the possible cause and consequences of the observed manifestations.

Keywords: concrete, corrosion, pathological manifestation, acid attack, case study. 


\section{Introdução}

O concreto é um material muito utilizado na construção civil devido a sua versatilidade construtiva, suas propriedades mecânicas e custo competitivo quando comparado a outros materiais de função estrutural, como madeira ou aço. Entretanto, quando o concreto é exposto a ambientes com classe de agressividade elevada, ele se torna vulnerável, pois os agentes agressores interferem diretamente na microestrutura da pasta do cimento, danificando concreto e, consequentemente, a armadura [1] [2].

Por consequência, são necessários cuidados especiais nas fases de projeto, construção e operação para que o concreto atenda as exigências de desempenho preconizadas em normas. Para tanto, o mesmo requer ponderação nas etapas de análises dos materiais que serão utilizados na sua composição. Ajustes de dosagem, aditivos para minimizar a retração e preocupações quanto ao calor de hidratação são indispensáveis, assim como a análise do ambiente em que a estrutura estará, pois isto influencia diretamente nas especificações do concreto e das proteções para alcançar a durabilidade pretendida [1].

Em uma Estação de Tratamento de Esgoto - ETE, a exposição do concreto a ação de esgoto sanitário doméstico caracteriza um ambiente de agressividade muito forte, classe IV [4], devido ao microclima formado no seu interior conter considerável concentração de ácido sulfúrico biogênico $-\mathrm{H}_{2} \mathrm{SO}_{4}$, responsável pela deterioração do concreto da estrutura [2].

O presente trabalho tem como objetivo apresentar e analisar os tipos de manifestações patológicas presentes em uma estação de tratamento de esgoto, localizada em Curitiba, na região do Santa Quitéria em Curitiba, dentro do reator tipo UASB. Este reator, construído em concreto armado, compõe um sistema de tratamento de esgoto doméstico, que, devido à alta agressividade do meio, é fortemente atacado por agentes agressivos.

\section{ATAQUES QUÍMICOS EM UM SISTEMA DE REATOR UASB}

A estação de tratamento de Esgoto (ETE) é o local destinado para tratamento de esgoto doméstico. Constituído basicamente por um tanque de concreto armado, que na parte superior são acoplados um decantador e defletor de gases formados [5].

Em um reator UASB e manta de lodo, ocorre a formação de ácido sulfídrico (H2S) e Anidrido carbônico (CO2) a partir de compostos orgânicos contendo enxofre como cisteína, cistina e metionina, presentes no esgoto doméstico através da ação de bactérias anaeróbias redutoras de sulfato (dessulfatação). O sulfeto de hidrogênio (H2S) ou gás sulfírdrico, oriundos da reação está associado à produção de odores desagradáveis, é extremamente tóxico além de ser o precursor para a formação de ácido sulfúrico (H2SO4), que corroe o concreto [6]. Uma parte do ácido sulfídrico que se desprende do efluente na forma gasosa reage com o oxigênio do ar atmosférico formando compostos de enxofre (S2O3-2, S4O6-2, SO4-2). Segundo [7], a outra parte formará ácido (H2SO4), por via biológica, através de microorganismos como o Thiobacillus concretivorus. As bactérias são autotróficas, necessitando como nutrientes apenas o enxofre, gás carbônico, oxigênio, sais 
minerais e água, para produzir, assim, o ácido sulfúrico, o qual reage com o carbonato de cálcio originando o estufamento e desagregação do concreto. A degradação é mais acentuada na região adjacente ao nível do efluente e desprezível na região submersa [2]. De acordo com [8] não é habitual o contato do concreto com ácidos em altas concentrações. Contudo, a ação de chuvas ácidas nos grandes centros urbanos e nas áreas industriais acaba por ser mais freqüente, causando danos a estrutura de concreto.

Os fluidos agressivos podem penetrar nos poros do concreto de três formas, [10]:

01) por meio da difusão, que se trata do resultado da diferença existente dos graus de concentrações iônicas entre os fluidos externos e internos;

02) por pressão hidrostática, que é o resultado da diferença relativa a variação na pressão dos fluidos;

03) por existência de forças capilares, resultantes da ocorrência de mecanismos capilares;

A penetração destes fluidos pode ser resultado também de uma combinação de forças, potencialmente influenciadas por variação de temperaturas ou até mesmo da existência de correntes elétricas [10].

Segundo [11], as reações químicas se manifestam através de efeitos físicos nocivos, tais como o aumento da porosidade e da permeabilidade, com a diminuição da resistência, presença de fissuração e destacamento, sendo requerida atenção especial para o ataque de sulfatos e ataque por álcali-agregado inclusive pela corrosão das armaduras, uma vez que estes fenômenos são responsáveis pela deterioração de uma das estruturas de concreto.

\subsection{Ataque de Ácido Sulfúrico}

Os ácidos possuem um mecanismo de ação sobre o concreto atuando de maneira destrutiva sobre a superfície porosa do mesmo e produzindo uma transformação completa na pasta de cimento endurecida. Com isso, o resultado destas ações causa a perda de massa cimentícia gerando também a redução da seção do concreto, em camadas sucessivas (e a partir da superfície exposta) sendo a velocidade da degradação proporcional à quantidade e concentração do ácido que está em contato com o concreto. [8].

O ácido sulfúrico reage com o cimento das paredes do reator, formando uma pasta que desestabiliza as ligações com os agregados inertes do concreto, e se espalha por toda a superfície acima do nível do líquido. Isso faz com que se desprenda a camada de cobrimento do concreto, por seu próprio peso, ou por arraste quando o nível de líquido (esgoto) sobe [6].

\subsection{Ataque de Sulfato}

Os sulfatos podem ter origem nos materiais que compõe o concreto ou no contato do concreto com os solos ou águas ricas com este agente. $O$ ataque produzido por sulfatos é devido a sua ação expansiva, que pode gerar tensões capazes de fissurálo. Os sulfatos podem estar na água de amassamento, nos agregados ou no próprio 
cimento. Eles podem penetrar desde o exterior por difusão iônica ou por sucção capilar [12].

A presença de sulfatos solúveis, principalmente aqueles de sódio, cálcio e magnésio, é comum em áreas de operação de minas e indústrias químicas. Sódio e cálcio são os sulfatos mais comuns nos solos, em águas e processos industriais. Sulfatos de magnésio são mais raros, porém mais destrutivos. Todos os sulfatos são potencialmente danosos ao concreto, reagindo com a pasta de cimento hidratado. No ataque, os íons sulfatos reagem principalmente com o hidróxido de cálcio $\mathrm{Ca}(\mathrm{OH}) 2$ e o aluminato tricálcico $\mathrm{C} 3 \mathrm{~A}$, originando a etringita e o gesso. Esta formação expande-se, exercendo pressão e desintegrando a pasta de cimento [13].

Segundo [9], pode- se aumentar a resistência do concreto contra o ataque de sulfatos através da redução do fator água/cimento, com o uso de cimento resistente à sulfatos, com baixo teor de aluminato tricálcico, e com a introdução de proporções adequadas de sílica ativa e cinzas volantes.

\section{Tipos de Manifestações Patológicas}

\subsection{Carbonatação}

O anidrido carbônico CO2 dissolvido na água que está presente no ar atmosférico, forma o ácido carbônico (H2CO3) penetrando pelos poros do concreto causando a carbonatação, que é a diminuição da alcalinidade da pasta de cimento. Através da lixiviação dos compostos cimentícios que reagem com os componentes ácidos da atmosfera resultando na formação de carbonatos. Em virtude disso o concreto adquire a camada carbonatada mais espessa, pois, quanto maior for a concentração de CO2 menor será o pH, podendo resultar na fissuração do concreto e destacamento do cobrimento do aço [14].

Segundo [15].o pH ideal do concreto para fornecer proteção a armadura está entre 12,5 à 13,5, por este ser altamente alcalino. Quando o pH é reduzido, a frente de carbonatação se direciona ao interior do concreto até a armadura, causando sua expansão e prejudicando a aderência e desagregando o concreto. Assim, a película passsivadora do aço é rompida podendo ocorrer a corrosão [14].

\subsection{Corrosão}

A armadura deve ser protegida do ar pelo cobrimento do concreto, no entanto, isto não é o suficiente para sua total proteção, principalmente quando a estrutura é exposta a ambientes altamente agressivos. A corrosão pode ocorrer por um processo químico ou eletroquímico associado ou não a esforços mecânicos. As células de corrosão podem ser geradas de duas formas, uma delas composta pela junção de dois metais diferentes no concreto e a outra devido à concentração de íons dissolvidos, como cloretos e álcalis. Este processo ocasiona um produto de corrosão (ferrugem) que dependendo do grau de oxidação aumenta seu volume em até $600 \%$ em relação a sua bitola original, causando a expansão da armadura e fissuração do concreto [16]. 


\subsection{Erosão}

Segundo [14], o desgaste por ação do escoamento de fluidos que contenham partículas sólidas em suspensão pode ser definido como Erosão. A gravidade do fenômeno se dá em virtude do tamanho, forma, densidade, dureza e velocidade das partículas que atritam o concreto através de escorregamento, rolamento ou colisão. De uma forma geral, a pasta de cimento não dispõe de alta resistência ao atrito. Para a minimização deste desgaste é necessário que a pasta do cimento possua elevada resistência, e baixa porosidade.

As erosões são causadas pela desintegração progressiva do concreto por ação da abrasão, lixiviação ou ataques químicos. Ela se agrava devido aos agentes químicos presentes no esgoto também causarem este tipo de manifestação patológica. Esse desgaste da estrutura pode ser classificado em três tipos: superficial, médio e profundo. $O$ desgaste superficial acontece quando existe uma perda parcial do cobrimento, apesar disso, os agregados graúdos não são expostos. Já o médio, provoca o aparecimento dos agregados graúdos, mas não existe exposição da armadura. No desgaste superficial profundo, acontece uma perda total do cobrimento e aparecimento da armadura [17].

\section{Metodologia}

O desenvolvimento deste trabalho baseou-se em uma revisão bibliográfica e estudo de caso sobre as manifestações patológicas mais comuns em uma Estação de Tratamento de Esgoto, pelo sistema de saneamento anaeróbio em um Reator do tipo UASB (UpflowAnaerobicSludgeBlanket), com o objetivo de verificar os agentes agressores, as causas mais comuns de patologia e análise dos problemas patológicos encontrados. O levantamento de dados teve início com a visita técnica na ETE em Curitiba, na região do Santa Quitéria. Posteriormente, foi efetuado pesquisas por meio eletrônico, livros de autores renomados, bem como em dissertações, publicações de revistas e boletins técnicos.

Para elaboração deste estudo de caso foram identificadas de forma visual as manifestações patológicas e, através de registros fotográficos e orientações técnicas, foi possível detectar as alterações ocorrentes na estrutura, conforme segue:

a) Corrosão: Um ambiente agressivo e úmido colabora para a deterioração do aço. A presença de microrganismos em meio aquoso pode modificar as propriedades principais do metal. No UASB estudado foram encontrados vários pontos com esta manifestação patológica. Como visto, (Fig. 1) a armadura exposta está totalmente corroída, e foi verificada a armadura da estrutura parcialmente exposta (Fig. 2), e com quantidade elevada de corrosão. Foi visto também esta manifestação patológica na parte externa do UASB.

b) Erosão: Na parede da estrutura do UASB, foi constatado erosão provavelmente causada pelo atrito das partículas presente no esgoto em movimento. Foi possível perceber que a erosão encontra-se em um nivel de desgaste médio (Fig. 3), pois a erosão expôs os agregados graúdos e não atingindo ainda na armadura. 


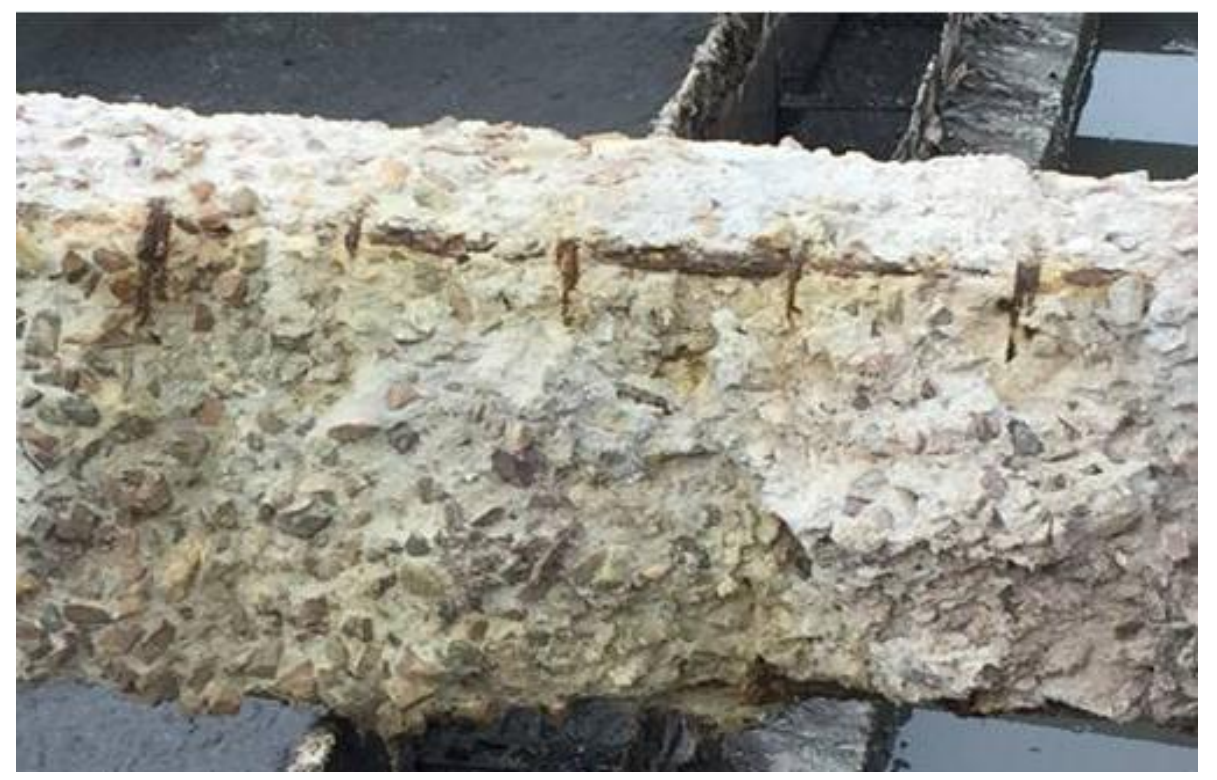

Figura 1: Viga do UASB com a armadura exposta altamente corroída

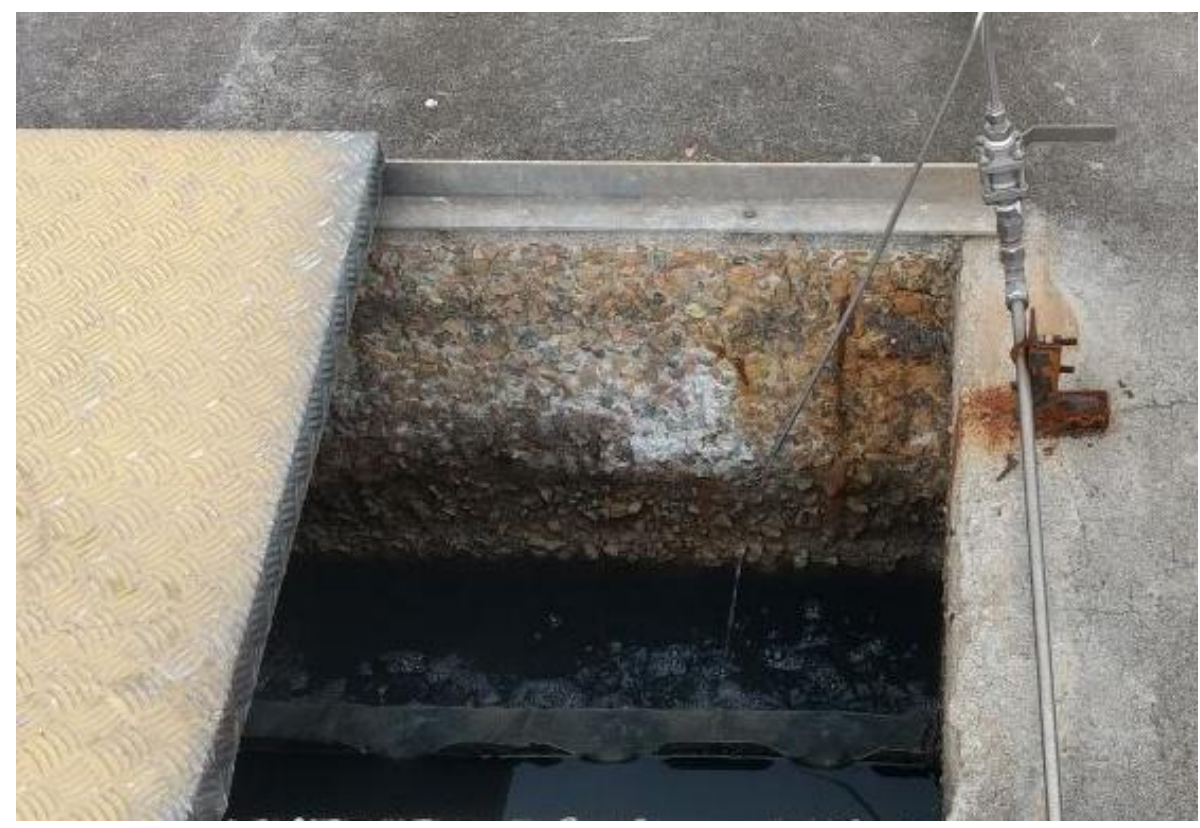

Figura 2: Armadura parcialmente exposta e a parte externa também corroída.

c) Ataque por sulfato: Os sulfatos podem ter origem nos materiais que compõem o concreto ou no contato do concreto com o ambiente que possui este agente. No UASB o problema é frequente, visto que a água do esgoto pode levar esses íons para as estruturas de concreto. Este íon reage quimicamente com os compostos do cimento formando um produto expansivo, que provoca a fissuração e desagregação do concreto. Na visita técnica, foi possível verificar a deterioração da superfície de concreto (Fig. 3), com visível exposição dos agregados possivelmente decorrentes do ataque por sulfatos. 


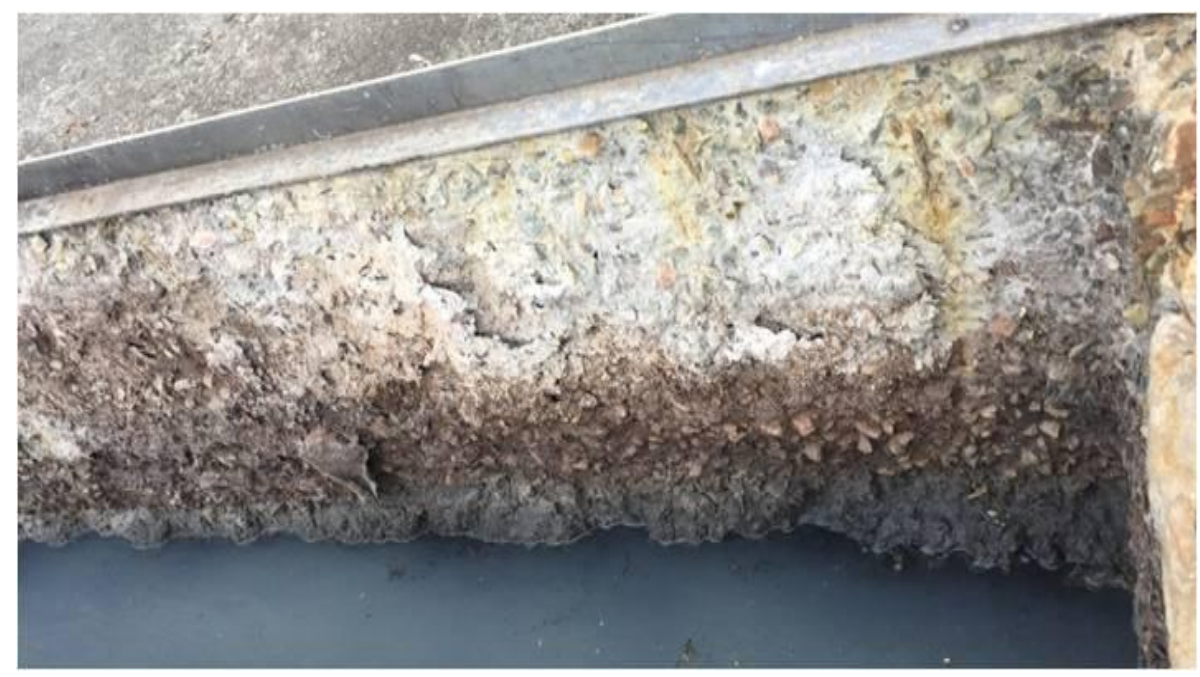

Figura 3: Erosões na parede da estrutura UASB

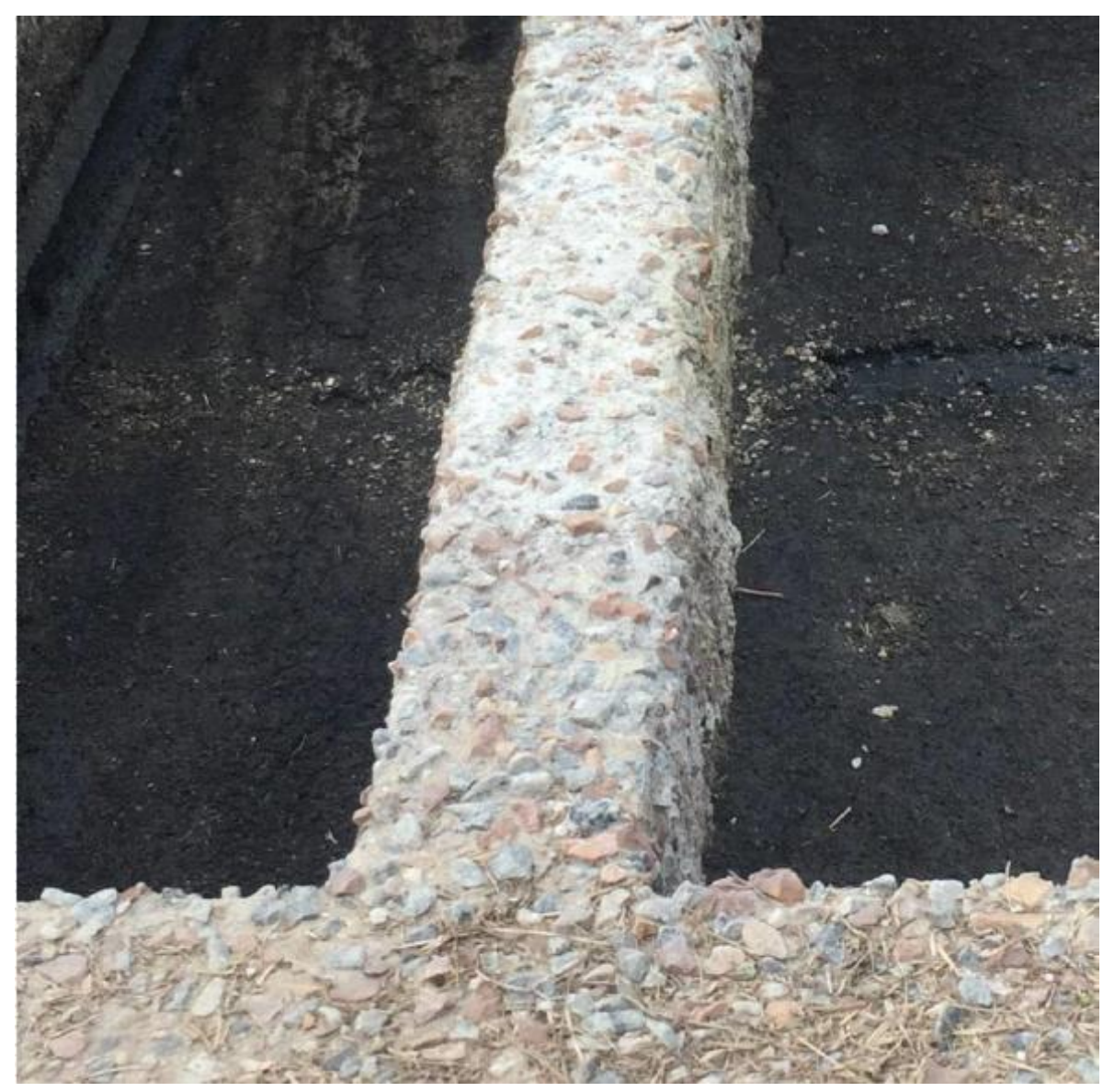

Figura 4: Viga deteriorada por ataque de sulfatos no reator tipo UASB

d) Carbonatação: Foram identificadas manchas brancas na parede da estrutura (Fig. 5), que tendem a ser carbonato de cálcio. Entretanto, este fenômeno só pode ser confirmado após ensaio específico com Fenolftaleína. 


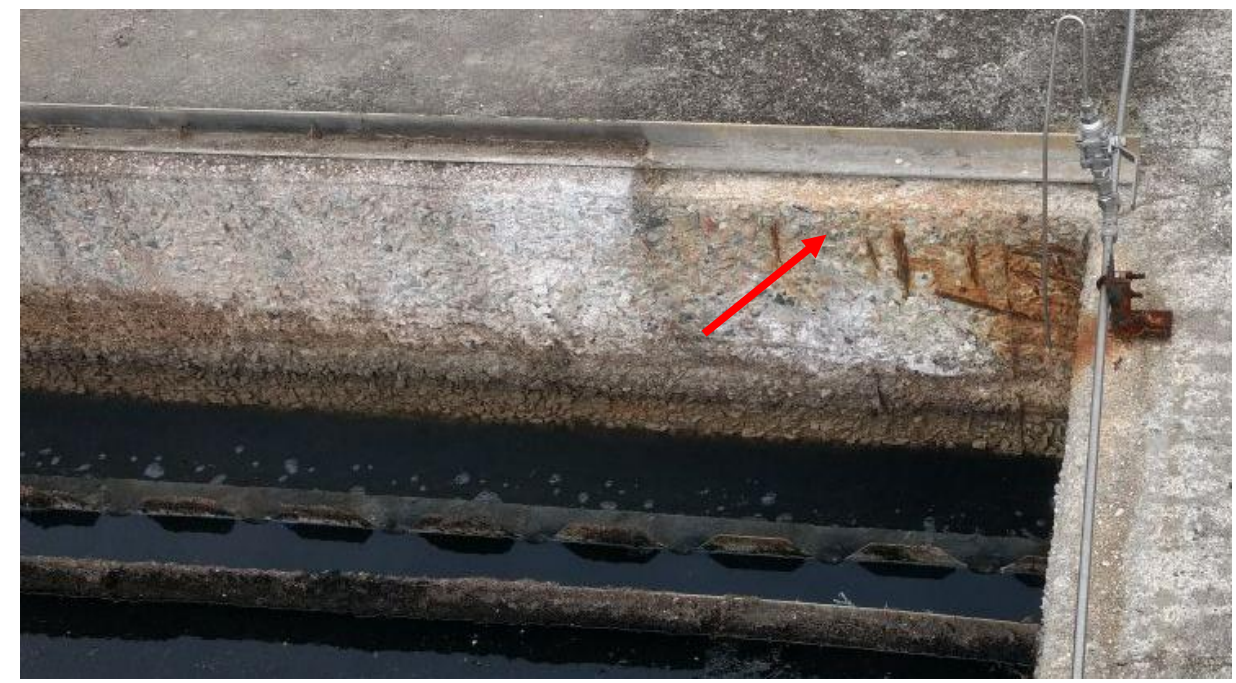

Figura 5: Parede da estrutura do UASB com suspeita de carbonatação

\section{Conclusão}

Em virtude da realização dos estudos realizados em relação ao ataque químico e à influência do H2S na formação do ácido sulfúrico biogênico, agressor em potencial à estrutura, considerando a atuação direta na superfície de concreto, visualmente observadas, especificamente na dos reatores tipo UASB em estações de tratamento de esgoto sanitário, pôde-se verificar o elevado grau de agressividade do meio diante de tais estruturas.

Foi possível identificar as manifestações patológicas e as não-conformidades por meio visual e fotográfico. Entretanto, para afirmações mais concisas sobre a magnitude dos mecanismos que a estrutura está sujeita a deterioração, sugere-se que sejam realizados ensaios mais específicos como: o Microscopia Eletrônica por Varredura - MEV, Difração de Raio X, Resistência à Compressão e ensaio com Fenolftaleína. Os ensaios contemplam uma condição melhor para a análise mais propícia com o intuito de efetuar a confirmação das possíveis causa e consequências das manifestações observadas.

\section{Agradecimentos}

Os autores agradecem à Companhia de Saneamento do Paraná, pelo apoio na concessão das autorizações de acesso e utilização dos dados da ETE, à Universidade Federal do Paraná através do Prof. Dr. Marcelo Medeiros e Faculdade Educacional Araucária.

\section{Referências}

[1] Silva Filho, L. C. Durabilidade do concreto à ação de sulfatos: análise do efeito da permeação de água e da adição de microssílica. 2014. 136 p. Dissertação (Mestrado). Curso de Pós-Graduação em Engenharia Civil da Universidade Federal do Rio Grande do Sul, Porto Alegre, 2014. 
[2] Hoppe Filho, J.; et al. Degradação do concreto de uma Estação de Tratamento de Esgoto (ETE) por ácido sulfúrico biogênico. Revista ALCOPAT, v. 4, n. 2, mai -ago. 2014. p. 84-96.

[3] Corsini, R. Ambientes agressivos. Revista Téchne. ed. 196. São Paulo. Jul. 2013.

[4] Associação brasileira de normas técnicas - NBR. 6118: Projeto de estrutura de concreto: procedimento. Rio de Janeiro, 2007.

[5] Souza, M.E.; Vieira, S.M.M. Reator Uasb para tratamento de esgoto sanitário. Revista DAE. V.46, n.145. São Paulo, 1986. <http://www.revistadae.com.br/artigos/artigo_edicao_145_n_180.pdf> Acesso em: 22 fev. 2018.

[6] Sobrinho, P.A.; Tsutiya, M.T. Coleta e transporte de esgoto sanitário. 2a ed. São Paulo,Departo de Engenharia Hidráulica e Sanitária da Escola Politécnica da Universidade de São Paulo, ISBN, 8590082318, 9788590082316. 547p. 2000.

[7] Aisse, M. M. Sistemas econômicos de tratamento de esgotos sanitários. In: ASSOCIAÇÃO BRASILEIRA DE ENGENHARIA SANITÁRIA E AMBIENTAL ABES, Rio de Janeiro.2000, 192p.

[8] Andrade, J.J.O; et al. Avaliação das características do concreto quando submetido à degradação de origem química. In: Congresso Brasileiro do Concreto- REIBRAC, 45, 2003, Vitória - ES. Anais. São Paulo: IBRACON, 2003 (CD ROM).

[9] Emmons, P. H. Concrete Repair and Maintenance. Kingston: R. S. Means Company, 1993. 295 p. ISBN 0- 87629- 286- 4.

[10] Ferreira, R. M. Avaliação dos ensaios de durabilidade do betão. 2000. 246 f. Dissertação de Mestrado em Engenharia Civil - Escola de Engenharia, Universidade do Minho, Braga, 2000.

[11] Mehta, P. K.; Monteiro, P. J. M. Concreto: Estrutura, Propriedades e Materiais. Tradução de Paulo Helene et al. 1ª ed. São Paulo, PINI, 1994. 580p. ISBN 857266-040-2.

[12] Silva, T. J. Predicción de la vida útil de forjados unidireccionales dehormigón mediante modelos matemáticos de deterioro 1998. 290f. Tese (Doutorado em Engenharia Civil) - Escola técnica superior d'enginyers de Camins, Universidade Politécnica da Catalunya, Barcelona, 1998.

[13] Lapa, J. S. Patologia, Recuperação e Reparo das Estruturas de Concreto, Escola de Engenharia, Universidade Federal de Minas Gerais, Belo Horizonte, 2008.

[14] Ribeiro, D.V.; et al. Corrosão em estruturas de concreto armado: teoria, controle e métodos de análise. Rio de Janeiro: Elsevier. 2014.

[15] Cunha, A.C.Q.; Helene, P.R.L. Despassivação das armaduras de concreto por ação da carbonatação. Boletim técnico da Escola Politécnica da Universidade de São Paulo - BT/PCC/283. São Paulo, 2001

[16] Mehta, P. K.; Monteiro, P. J. M. Propriedades e Materias. 2ª Ed. Ibracon, 2008. 
KUDLANVEC JUNIOR, V.L. et al., LEVANTAMENTO DE MANISFESTAÇÕES PATOLÓGICAS EM ESTAÇÃO DE TRATAMENTO DE ESGOTO: ESTUDO DE CASO EM REATOR UASB. $3^{\circ}$ Simpósio Paranaense de Patologia das Construções ( $3^{\circ} \mathrm{SPPC}$ ), artigo 3SPPC1010, pp. 106 - 115, 2018. DOI: 10.4322/2526-7248.010

[17] Dyer, T. A durabilidade do concreto. 1를. Rio de Janeiro Ciência Moderna, 2015. 